\title{
Research collaboration in health management research communities
}

\author{
Chichen Zhang ${ }^{1}$, Qi Y ${ }^{2}$, Qinghua Fan ${ }^{3}$ and Zhiguang Duan ${ }^{4^{*}}$
}

\begin{abstract}
Background: This study uses scientometrics methodology to reveal the status quo and emerging issues of collaboration in health management.

Methods: We searched all the articles with the keyword "health management" in the period 1999-2011 in Web of Knowledge, then 3067 articles were found. Methods such as Social network analysis (SNA), co-authorship, co-word analysis were used in this study.

Results: Analysis of the past 13 years of research in the field of health management indicates that, whether the production of scientific research, or authors, institutions and scientific research collaboration at the national level, collaboration behavior has been growing steadily across all collaboration types. However, the international scientific research cooperation about health management study between countries needs to be further encouraged. 17 researchers can be seen as the academic leaders in this field. 37 research institutions play a vital role in the information dissemination and resources control in health management. The component analysis found that 22 research groups can be regarded as the backbone in this field. The 8 institution groups consisting of 33 institutions form the core of this field. USA, UK and Australia lie in the center by cohesive subgroup analysis; Based on keywords analysis, 44 keywords with high frequency such as care, disease, system and model were involved in the health management field.

Conclusions: This study demonstrates that although it is growing steadily, collaboration behavior about health management study needs to be enhanced, especially between different institutions or countries/regions, which would promote the progress and internationalization of health management. Besides, researchers should pay attention to the cooperation of representative scholars and institutions, as well as the hot areas of research, because their experience would help us promote the research development of our nation.
\end{abstract}

Keywords: Health management, Co-authorship, Network, Collaboration

\section{Background}

The idea and practice of health management originated from America in 1950s, and then sprung up as an emerging subject in UK, Germany, France, Japan etc. In the 21st century, health management spread in the developing countries and was applied in government, business, medical institutions and the insurance industry. Now it has become a prospective health service model for many countries to improve their national health level and promote the society's sustainable development. Along with the increasingly popularity of health management,

\footnotetext{
* Correspondence: dzg528@yahoo.com.cn

${ }^{4}$ School of Public Health, Shanxi Medical University, South Xinjian Road, Taiyuan, China

Full list of author information is available at the end of the article
}

research collaboration in this field has also increased. Research collaboration is becoming an important way of improving health management by extensive cooperation, which makes resources sharing and knowledge stocking possible. However, the co-authorship analysis in this field is seldom reported. Thus, the status quo of international collaboration in health management was revealed by scientometric methodology in this study.

\section{Literature review}

It has been argued that co-authorship do not provide the entire view of the process of collaboration, however it is still advantageous for collaboration analysis through co-authorship as it is inexpensive and practical [1-4].

\section{Biomed Central}


Co-authorship can be analyzed at three levels (authors, institutions and countries/regions), such as the analysis of different countries/regions, institutions and authors for a certain time. It is a way to reveal the interrelationships of the domain, the intensity of these relations $[5,6]$. Also, all sorts of methods are applied to this field, including the frequently used Bibliometric techniques and social network analysis, as well as some new methods. Moreover, Zaida Chinchilla-Rodríguez had used blockmodeling to study the internal structure of co-authorship networks in the micro-level in 2012 [7].

Publications with more than one author have been on the rise, with many studies showing this trend [8-11]. However, these trends are not uniform, and must be contextualized by domain, country conditions and field of study [12-17]. Research in this respect has shown that there is a rise in institutional collaboration [18], but with the full caveats that this varies by discipline [19]. Especially in the biomedical fields, it tends to have high degrees of collaboration between institutions domestically, but not internationally [20].

The increase in international collaboration is not only a trend of the 21st century, but one that has been noted in scientometric studies for over a decade [21-26]. However, very few studies examined the collaboration activities in Health Management research field across multiple collaboration types [27-31]. This study intends to address this issue.

\section{Research questions}

We intended to reveal current status of the collaboration activities and research topics in the Health Management field by using the method of co-authorship and co-word analysis so as to provide scientific evidence on research collaboration and suggestions for policymakers to establish a more efficient system for guiding and funding the Health Management research in the future.

Research Question 1:

What is the research collaboration trend in Health Management research?

Research Question 2:

Who/which are the most collaborative authors, institutions and countries/regions in Health Management research?

Research Question 3:

What are the research topics in Health Management research?

\section{Data and methods \\ Date collection}

The documents which contain the word "Health Management" in their title, abstract or keywords were collected from the scientific literature database "Web of Knowledge". The scope was limited to the years 1999 through
2011. All documents regardless of type (e.g. article, meeting abstract, proceedings paper, review, editorial material, book review, letter, note, etc.) were processed. All documents from the Science Citation Index Expanded (SCI-Expanded), Social Sciences Citation Index (SSCI), Arts \& Humanities Citation Index (A\&HCI), Conference Proceedings Citation Index-Science (CPCI-S), and Conference Proceedings Citation Index-Social Science \& Humanities (CPCI-SSH) were taken into account. The query yielded 3067 records, each of which has author names, affiliations, titles, sources, abstracts, total citations, key words and cited references.

\section{Data Refinement}

Articles coauthored by authors from more than one institution were classified as multi-institutional collaboration. A paper coauthored by authors from different countries/regions was considered a multi-national paper.

The names of authors and institutions have been normalized manually. For example, Zhao Y from Shanghai Univ was labeled "Zhao Y 1", while Zhao Y from Sch Management Beihang Univ was labeled "Zhao Y 2". Different variations of institution's name were assigned to one name.

Keywords Plus (Web of Knowledge supplied keywords in capital letters) is used in this paper.

\section{Methods}

In our previous studies, we revealed the collaboration activities in the oncology research field and cardiology and cardiovasology research field by means of coauthorship analysis, social network analysis and keyword analysis. We believe that these studies can provide suggestions for policy-maker in medical research management.

\section{Bibliometrics}

Bibliometrics is a quantitative analysis method by processing the literatures' characteristics and using mathematics and statistics methods to describe, evaluate and predict the status and future of science and technology.

\section{Social network analysis}

Social network is a network of individuals' communication including nodes and ties, especially for gaining one's specific ends. The node represents the individual or institution in the network, while the tie represents the content or way of communication [32,33]. Social network analysis (SNA) is the methodical analysis of social networks. Social network analysis views social relationships in terms of network theory, consisting of nodes (representing individual actors within the network) and ties (which represent relationships between the individuals, such as friendship, kinship, organizational position, sexual relationships, etc.) [34-37]. 
Pajek, a visualization toolkit for large-scale networks, was applied to map the collaboration. The node size in the graph is proportional to number of productions by authors, institutions or countries/regions, and the thickness of the lines represents the number of co-published papers.

\section{Centrality}

Centrality is an important index to analyze the network. Whether the individual or institution lies in the center of social network will determine its influence on the network and its speed to gain information. Centrality measure includes degree centrality, closeness centrality, and betweenness centrality.

Degree Centrality of is defined as the number of ties that a node has. Degree Centrality represents the simplest notion of Centrality since it is just the number of neighbors of a node in the network.

The Closeness Centrality of a node is the number of others nodes divided by the sum of all geodesic distances between the node and all others, where larger distances yield lower Closeness Centrality scores. The closer a node is to all other nodes, the easier information may reach it, the higher its Centrality.

Betweenness Centrality rests on the idea that a node is more central if he is more important as an intermediary in the network. The Betweenness Centrality of a node is the proportion of all geodesics between pairs of other nodes that include the node.

The three centrality metrics can help us identify the "important" persons or organizations in the network.

\section{$\mathrm{N}$-cliques and $\mathrm{M}$-core}

$\mathrm{N}$-cliques insists that every member or a sub-group have a direct tie with each and every other member. M-core is a cohesive subgroup which meets the requirements that all line value in the subgroup are no less than $\mathrm{M}$.

\section{Keyword co-occurrence analysis}

Methods such as co-citation analysis, bibliographic coupling analysis and keyword analysis can be used to reveal the hot research topics. Co-citation analysis, bibliographic coupling analysis are two citation-based approaches. As many of our records have no citations, we chose keyword analysis in our study. If two keywords co-occur in many articles, it implies the close links between the topics to which they refer. Therefore, the analysis of the keyword co-occur frequency could reflect the relationship of the subjects. The keyword co-occurrence has been used in many studies to reveal research hot topics of some specific field or discipline [38-42]. In this study, keyword co-occurrence was used to provide an immediate picture of research collaboration topics in health management field.

\section{Results}

The trends of scientific production in the area of health management

From 1999 to 2011, the total amount of research papers in the field of health management has a significant growth (Figure 1). Figure 1 shows the total number of papers published annually. Overall, in 13 years the number of published articles increased by nearly six times from 62 in 1999 to 421 in 2011.

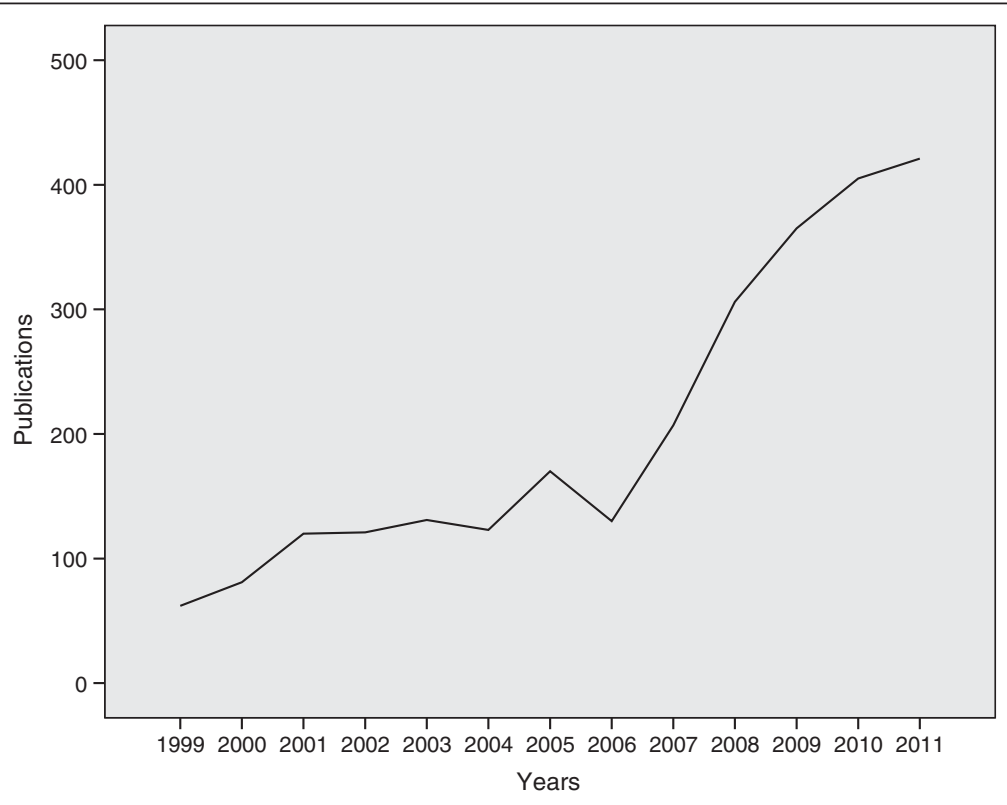

Figure 1 Evolution of publications in health management research from 1999 to 2011. 


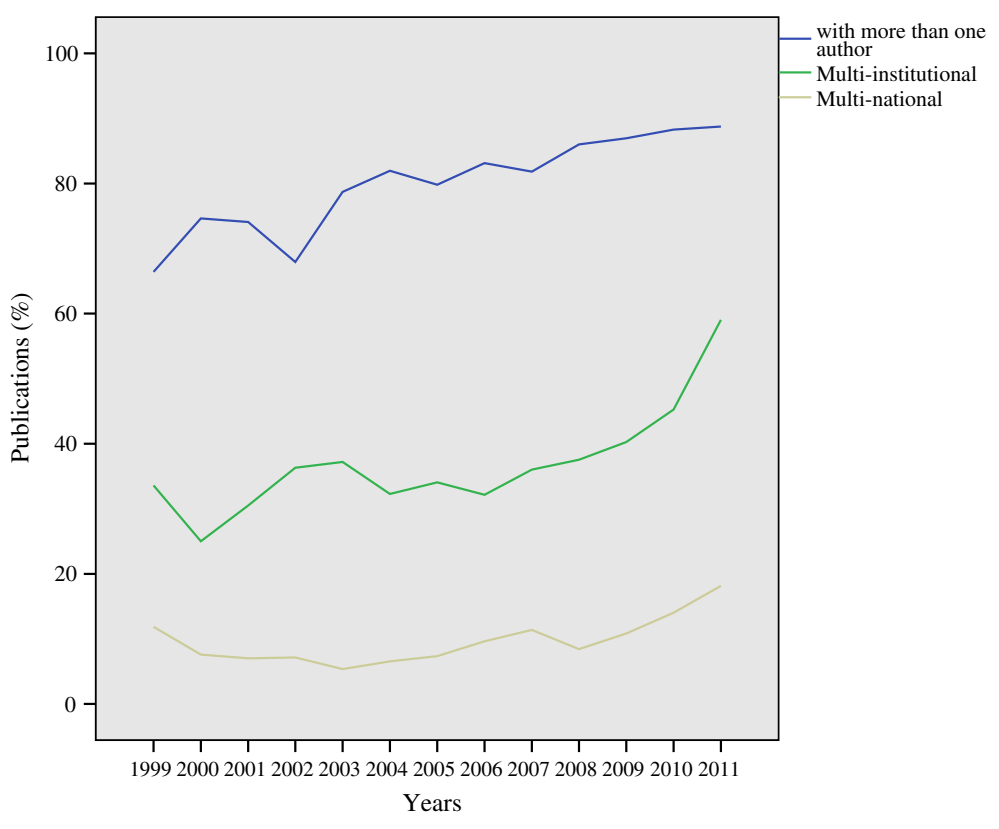

Figure 2 Percentage of multi-entity publications in health management research, 1999-2011.

\section{The analysis of cooperation trends}

\section{The trend of co-author}

Between 1999 and 2011, the collaboration among the staff of health management has increased significantly. Figure 2 displays the percentage of writers coauthored papers, institutions coauthored papers and nationality coauthored papers. Figure 3 reveals the change of the average article number for an author, institution or country. The ratio of coauthored papers increased from $66 \%$ in 1999 to $89 \%$ in 2011 . The ratio of institutions coauthored papers and national coauthored papers showed a similar trend of growth. However, the ratio of papers coauthored by writers is significantly higher than the other two resources. The quantity of the

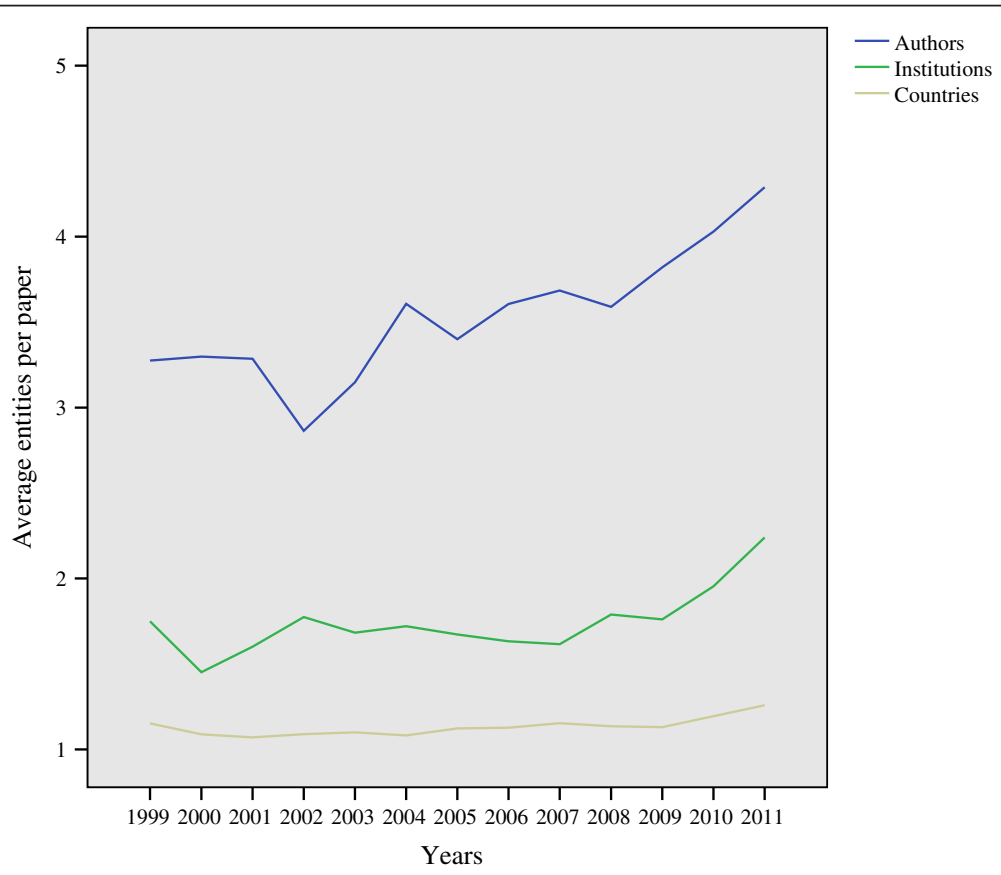

Figure 3 Average numbers of different entities per paper in health management research, 1999-2011. 
Table 1 Top 17 authors with high centralities

\begin{tabular}{ccccc}
\hline Rank & Authors & Degree & Closeness & Betweeness \\
\hline 1 & "O'Toole, T1" & 57 & 0.006160686 & $1.38332 \mathrm{E}-05$ \\
2 & "Ascher, MS" & 51 & 0.005938011 & $7.10807 \mathrm{E}-06$ \\
3 & "Tonat, K2" & 46 & 0.005764384 & $9.00965 \mathrm{E}-06$ \\
4 & "Osterholm, MT2" & 46 & 0.005764384 & $5.15801 \mathrm{E}-06$ \\
5 & "Perl, TM2" & 45 & 0.005730871 & $4.96446 \mathrm{E}-06$ \\
6 & "Hauer, J2" & 40 & 0.005568982 & $3.76404 \mathrm{E}-06$ \\
7 & "Layton, M3" & 40 & 0.005568982 & $3.76404 \mathrm{E}-06$ \\
8 & "Lillibridge, S" & 40 & 0.005187946 & $3.13349 \mathrm{E}-06$ \\
9 & "Arase, Y" & 39 & 0.004234148 & $8.41763 \mathrm{E}-06$ \\
10 & "Friedlander, AM" & 37 & 0.004831911 & $2.43051 \mathrm{E}-05$ \\
11 & "Swearingen, K" & 34 & 0.004401286 & $4.85667 \mathrm{E}-05$ \\
12 & "Byington, CS1" & 33 & 0.005189133 & $9.19832 \mathrm{E}-05$ \\
13 & "Eitzen, EM" & 29 & 0.005243137 & $3.0151 \mathrm{E}-05$ \\
14 & "Pecht, M1" & 28 & 0.004568423 & 0.00012659 \\
15 & "Schmaljohn, AL" & 28 & 0.004953315 & $1.21053 \mathrm{E}-05$ \\
16 & "Peters, CJ" & 28 & 0.004879751 & $6.25438 \mathrm{E}-06$ \\
17 & "Roemer, MJ" & 24 & 0.005683336 & $6.23491 \mathrm{E}-05$ \\
\hline & & & & \\
\hline
\end{tabular}

average article number for an author went up from 3.27 in 1999 to 4.29 in 2011.

\section{The trend of institutional co-authorship}

As mentioned above, in the field of health management research, the ratio of papers coauthored by institution grew from $34 \%$ in 1999 to $59 \%$ in 2011. Meanwhile, the average article number for institution climbed from 1.75 in 1999 to 2.24 in 2011.

\section{The trend of national co-authorship}

As shown in figure 2, the ratio of national coauthored papers in the field of health management research increased from $12 \%$ in 1999 to $18 \%$ in 2011 . Figure 3 shows, most of the papers are the achievements of cooperation within a country, and the average article number for a country increased from 1.15 in 1999 to 1.26 in 2011, which increased slowly compared with that of researchers coauthored papers and institutions coauthored papers.

\section{Collaborations among researchers Co-author network}

The co-authorship network in this study contains 9447 nodes (researchers), 22666 lines (co-author frequency). The maximum co-author frequency is 8 and the network density is 0.000508 .

\section{Centrality analysis}

There are 17 authors who ranked in top 100 of all the three centralities in the co-authorship network, measured by calculating the degree, closeness and betweenness centrality (See Table 1).

\section{Cohesive subgroup analysis}

The N-clique of co-authorship network in health management was shown in Table 2. The maximum clique is 31-clique and $91.66 \%$ of researchers belong to 9-clique or below. Moreover, the majority researchers belong to 2-clique, 3-clique and 4-clique, the number is 1428 , 1459,1352 respectively.

The M-core of co-authorship network in health management was shown in Table 3. The maximum core is 8-core. And the majorities are in 1-core, which contains 8181 researchers.

By component analysis of 70 researchers who are higher than 4-core in the co-authorship, 22 groups were found (Figure 4), which means that the authors in each group co-published no less than 4 papers. And the relations among researchers within those groups are tight and stable.

Table 2 The $\mathrm{N}$-clique of co-authorship network in health management

\begin{tabular}{|c|c|c|c|c|c|c|c|}
\hline $\mathrm{N}$-Clique & Freq & Freq $\%$ & CumFreq\% & $\mathrm{N}$-Clique & Freq & Freq $\%$ & CumFreq\% \\
\hline 0 & 512 & 5.42 & 5.42 & 11 & 118 & 1.25 & 94.63 \\
\hline 1 & 1009 & 10.68 & 16.10 & 12 & 117 & 1.24 & 95.87 \\
\hline 2 & 1428 & 15.12 & 31.22 & 13 & 84 & 0.89 & 96.76 \\
\hline 3 & 1459 & 15.44 & 46.66 & 14 & 74 & 0.78 & 97.54 \\
\hline 4 & 1352 & 14.31 & 60.97 & 15 & 48 & 0.51 & 98.05 \\
\hline 5 & 1141 & 12.08 & 73.05 & 17 & 47 & 0.50 & 98.55 \\
\hline 6 & 806 & 8.53 & 81.58 & 18 & 33 & 0.35 & 98.90 \\
\hline 7 & 469 & 4.96 & 86.55 & 21 & 22 & 0.23 & 99.13 \\
\hline 8 & 252 & 2.67 & 89.21 & 23 & 24 & 0.25 & 99.39 \\
\hline 9 & 231 & 2.45 & 91.66 & 25 & 26 & 0.28 & 99.66 \\
\hline 10 & 163 & 1.73 & 93.38 & 31 & 32 & 0.34 & 100.00 \\
\hline
\end{tabular}


Table 3 The M-core of co-authorship network in health management

\begin{tabular}{ccccc}
\hline M-Core & Freq & Freq\% & CumFreq & CumFreq\% \\
\hline 0 & 512 & 5.42 & 512 & 5.42 \\
1 & 8181 & 86.60 & 8693 & 92.02 \\
2 & 571 & 6.04 & 9264 & 98.06 \\
3 & 113 & 1.20 & 9377 & 99.26 \\
4 & 37 & 0.39 & 9414 & 99.65 \\
5 & 17 & 0.18 & 9431 & 99.83 \\
6 & 11 & 0.12 & 9442 & 99.95 \\
7 & 3 & 0.03 & 9445 & 99.98 \\
8 & 2 & 0.02 & 9447 & 100.00 \\
\hline
\end{tabular}

\section{Collaborations among research institutions}

\section{Multi-institutional collaboration network}

The institution collaboration network contains 2776 nodes (research institutions), 4461 lines. The maximum line value is 9 and the network density is 0.0011582 .

\section{Centrality analysis}

There are 37 institutions that ranked in top 100 in the network, by calculating of degree, closeness and betweenness centrality (See Table 4).

\section{Analysis of cohesive subgroups}

The N-clique of institution collaboration network in health management was shown in Table 5. The maximum is 16-clique. The $\mathrm{M}$-core of health management institution collaboration network was shown in Table 6. The maximum is 9-core. And the majorities are in 1-core, which contains 1932 institutions. By component analysis of the 33 institutions that are in 3-core or more, 8 groups were found (Figure 5).

\section{Collaboration among countries/regions Multi-national collaboration network}

The countries/regions cooperation network is structured by data analysis which contains 102 nodes (countries/ regions), 358 lines. The maximum frequency of co-nation is 18 and the network density is 0.0683243 .

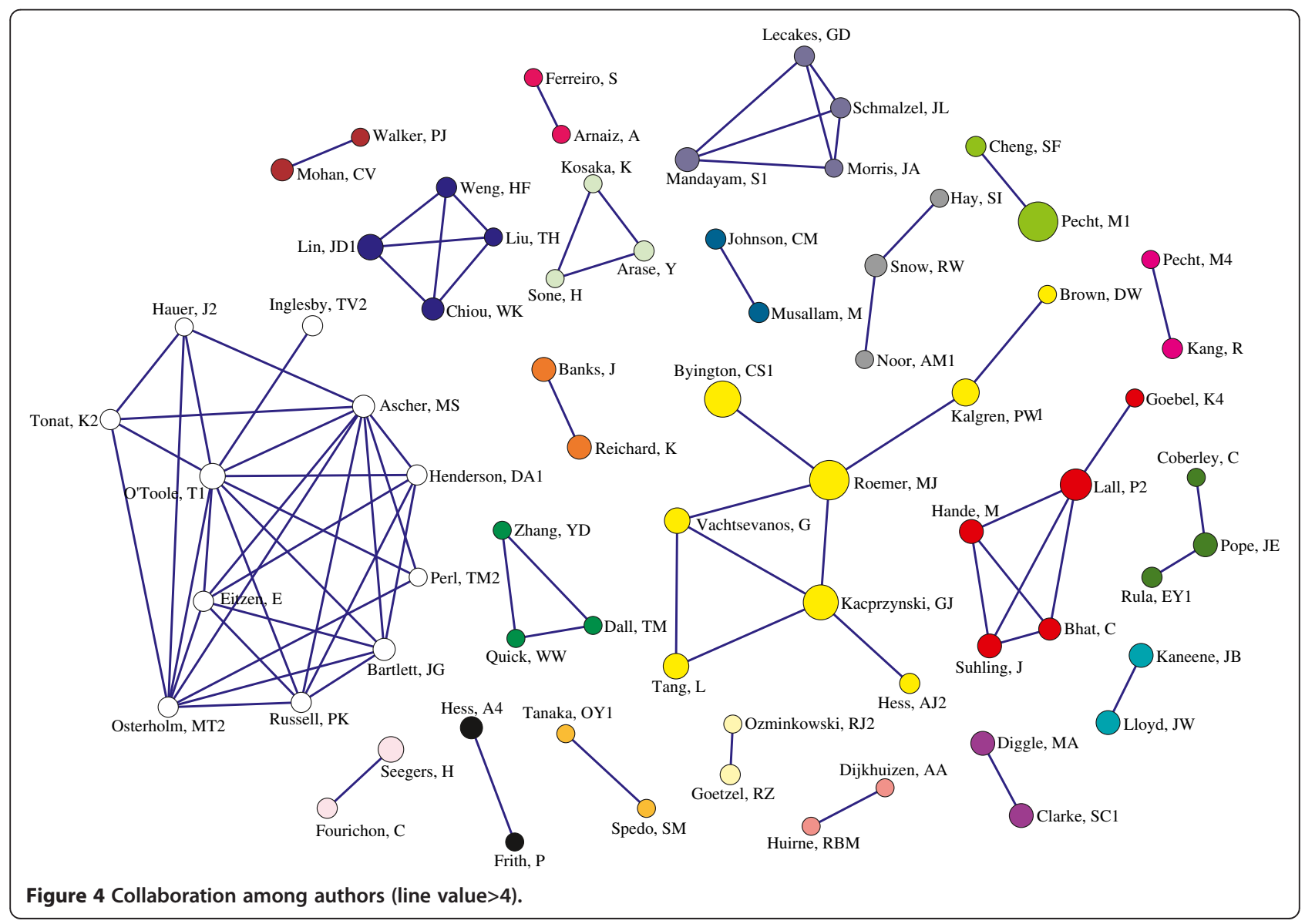


Table 4 Top 37 institutions with high centralities

\begin{tabular}{|c|c|c|c|c|}
\hline Rank & Org & Degree & Closeness & Betweeness \\
\hline 1 & UNIV MINNESOTA & 65 & 0.139536034 & 0.026331189 \\
\hline 2 & USAF & 61 & 0.133243448 & 0.020084938 \\
\hline 3 & UNIV WASHINGTON & 59 & 0.136385856 & 0.032965808 \\
\hline 4 & UNIV MARYLAND & 55 & 0.123266575 & 0.020476832 \\
\hline 5 & $\begin{array}{c}\text { CTR DIS CONTROL \& } \\
\text { PREVENT }\end{array}$ & 42 & 0.130342946 & 0.011750547 \\
\hline 6 & UNIV MICHIGAN & 40 & 0.122175917 & 0.015957716 \\
\hline 7 & WHO & 39 & 0.123311505 & 0.016469697 \\
\hline 8 & STANFORD UNIV & 38 & 0.13350636 & 0.029782294 \\
\hline 9 & COLUMBIA UNIV & 38 & 0.130670187 & 0.017456569 \\
\hline 10 & JOHNS HOPKINS UNIV & 34 & 0.128486561 & 0.020521669 \\
\hline 11 & UNIV ALABAMA & 32 & 0.125066586 & 0.008339021 \\
\hline 12 & UNIV MELBOURNE & 32 & 0.117405905 & 0.019133512 \\
\hline 13 & US DEPT HHS & 32 & 0.129817773 & 0.008307802 \\
\hline 14 & UNIV MISSOURI & 30 & 0.125484093 & 0.005603591 \\
\hline 15 & UNIV SO CALIF & 30 & 0.123423975 & 0.004564441 \\
\hline 16 & MINIST HLTH & 29 & 0.124217043 & 0.034480061 \\
\hline 17 & NORTHWESTERN UNIV & 29 & 0.128462166 & 0.022695165 \\
\hline 18 & MED COLL GEORGIA & 29 & 0.128291663 & 0.003952521 \\
\hline 19 & TEL AVIV UNIV & 27 & 0.118123294 & 0.008396166 \\
\hline 20 & $\begin{array}{l}\text { LONDON SCH HYG \& } \\
\text { TROP MED }\end{array}$ & 26 & 0.127927818 & 0.014331175 \\
\hline 21 & $\begin{array}{c}\text { BETH ISRAEL DEACONESS } \\
\text { MED CTR }\end{array}$ & 26 & 0.126209705 & 0.006820911 \\
\hline 22 & UNIV WISCONSIN & 24 & 0.121386837 & 0.007261674 \\
\hline 23 & UNIV WESTERN AUSTRALIA & 24 & 0.115857916 & 0.007170564 \\
\hline 24 & $\mathrm{NIH}$ & 24 & 0.131151431 & 0.007359746 \\
\hline 25 & UNIV ILLINOIS & 23 & 0.118661913 & 0.005502203 \\
\hline 26 & HARVARD UNIV & 22 & 0.120264883 & 0.014331563 \\
\hline 27 & ALBERT EINSTEIN COLL MED & 22 & 0.122729953 & 0.003980603 \\
\hline 28 & UNIV CALIF LOS ANGELES & 21 & 0.125740612 & 0.003765431 \\
\hline 29 & UNIV CALIF SAN FRANCISCO & 21 & 0.126021648 & 0.005312616 \\
\hline 30 & UNIV PENN & 20 & 0.130117352 & 0.018659974 \\
\hline 31 & BOSTON UNIV & 20 & 0.125717248 & 0.01613023 \\
\hline 32 & PENN STATE UNIV & 17 & 0.11763043 & 0.00749422 \\
\hline 33 & DUKE UNIV & 17 & 0.118516418 & 0.007325933 \\
\hline 34 & MCMASTER UNIV & 17 & 0.11857873 & 0.003277398 \\
\hline 35 & PALO ALTO MED FDN & 16 & 0.122774493 & 0.006299589 \\
\hline 36 & CHILDRENS HOSP & 15 & 0.118745214 & 0.007173336 \\
\hline 37 & UNIV COLORADO & 14 & 0.115561098 & 0.003574301 \\
\hline
\end{tabular}

\section{Analysis of cohesive subgroups}

The N-clique of countries/regions collaboration network in health management was shown in Table 7. The maximum is 9-clique. The M-core of multi-national collaboration network in health management was shown in
Table 5 The $\mathbf{N}$-clique of institution collaboration network in health management

\begin{tabular}{cccc}
\hline Cluster & Freq & Freq\% & Representative \\
\hline 0 & 651 & 23.451 & SCI MONITORING INC \\
1 & 594 & 21.3977 & UNIV ABERDEEN \\
2 & 544 & 19.5965 & BOEING CO \\
3 & 330 & 11.8876 & IMPACT TECHNOL LLC \\
4 & 190 & 6.8444 & UNIV GUELPH \\
5 & 171 & 6.1599 & MICHIGAN STATE UNIV \\
6 & 95 & 3.4222 & NASA \\
7 & 28 & 1.0086 & UNIV MICHIGAN \\
8 & 49 & 1.7651 & WHO \\
9 & 16 & 0.5764 & LONDON SCH HYG \& TROP MED \\
10 & 19 & 0.6844 & UNIV WISCONSIN \\
11 & 33 & 1.1888 & UNIV MARYLAND \\
13 & 25 & 0.9006 & UNIV WASHINGTON \\
14 & 14 & 0.5043 & USIV ALABAMA \\
16 & 17 & 0.6124 &
\end{tabular}

Table 8. The maximum is 19-core. And the majorities are in 1-core, which contains 41 countries/regions. The collaboration network among the 30 countries/regions was shown in Figure 6. And we can find that USA, UK, and Australia are at the core of the map.

\section{Analysis of hot research areas \\ Co-occurrence network}

The keywords co-occurrence network contains 4356 nodes (keywords), 31628 lines (frequency of co-occurrence). The maximum frequency of co-occurrence is 97 and the network density is 0.0033345 .

\section{Analysis of co-occur network}

As shown in Table 9, there are 44 keywords with frequency more than 20. Based on the m-core analysis, 44

Table 6 The M-core of health management institution collaboration network

\begin{tabular}{cccc}
\hline Cluster & Freq & Freq\% & Representative \\
\hline 0 & 651 & 23.451 & SCI MONITORING INC \\
1 & 1932 & 69.5965 & PENN STATE UNIV \\
2 & 151 & 5.4395 & NASA \\
3 & 23 & 0.8285 & MINIST HLTH \\
4 & 2 & 0.072 & UNIV SOUTHAMPTON \\
5 & 11 & 0.3963 & UNIV SAO PAULO \\
6 & 1 & 0.036 & JOHNS HOPKINS UNIV \\
7 & 3 & 0.1081 & PREVENT \\
9 & 2 & 0.072 & UNIV MARYLAND \\
\hline
\end{tabular}




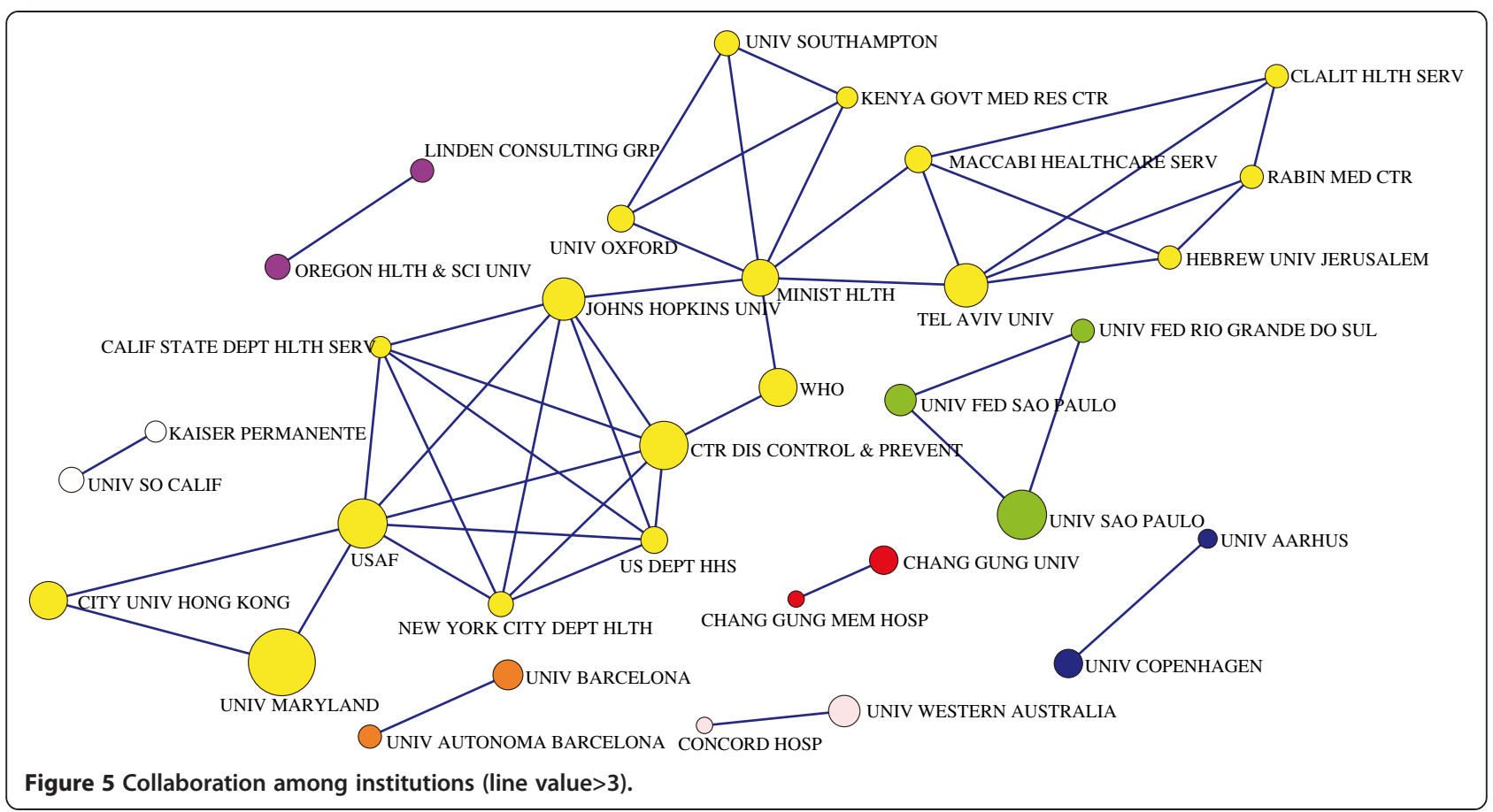

keywords which is higher than 6-core were selected to form the network of Figure 7.

The 44 keywords form a series of concentric circles with the most frequent sequence. Public Health Management, Care and Disease are placed in the center (Figure 7). Keywords in the innermost circle are those which have closest collaboration with Public Health Management. Keywords in the second innermost circle have closest collaboration with those which are in the innermost circle, and so on.

\section{Discussion}

\section{The analysis of cooperation trend}

Many studies have reported the ascending cooperation trend both in agencies and national cooperation. On the contrary, much less attention has been paid in the area

Table 7 The $\mathrm{N}$-clique of countries/regions collaboration network in health management

\begin{tabular}{cccc}
\hline N-clique & Freq & Freq $\%$ & Representative \\
\hline 0 & 17 & 16.67 & SERBIA \\
1 & 10 & 9.80 & CHILE \\
2 & 15 & 14.71 & MEXICO \\
3 & 7 & 6.86 & PAKISTAN \\
5 & 7 & 6.86 & KOREA \\
6 & 10 & 9.80 & BRAZIL \\
7 & 4 & 3.92 & CHINA \\
8 & 10 & 9.80 & CANADA \\
9 & 22 & 21.57 & USA \\
\hline
\end{tabular}

of health management. As far as papers coauthored by author, there was a relatively high degree of cooperation in the field of health management research, between 1999 and 2011, 81\% of output is the results of the research cooperation. Considering agencies and national cooperation level, however, the degree of cooperation is relatively lower, which has caused gaps by contrast with researcher cooperation level. Especially at the national level of cooperation, only $11 \%$ output is the results of international cooperation in the past 13 years, a little lower than 13\% output in the Coronary Heart Disease research field in our previous study [43]. Therefore, the

Table 8 The M-core of multi-national collaboration network in health management

\begin{tabular}{cccc}
\hline m-core & Freq & Freq $\%$ & Representative \\
\hline 0 & 18 & 17.4757 & SERBIA \\
1 & 41 & 39.8058 & FINLAND \\
2 & 14 & 13.5922 & BRAZIL \\
3 & 7 & 6.7961 & JAPAN \\
4 & 5 & 4.8544 & TAIWAN \\
5 & 5 & 4.8544 & SPAIN \\
6 & 3 & 2.9126 & ITALY \\
8 & 2 & 1.9417 & GERMANY \\
9 & 1 & 0.9709 & SCOTLAND \\
11 & 3 & 2.9126 & AUSTRALIA \\
17 & 1 & 0.9709 & CHINA \\
19 & 3 & 2.9126 & USA \\
\hline
\end{tabular}




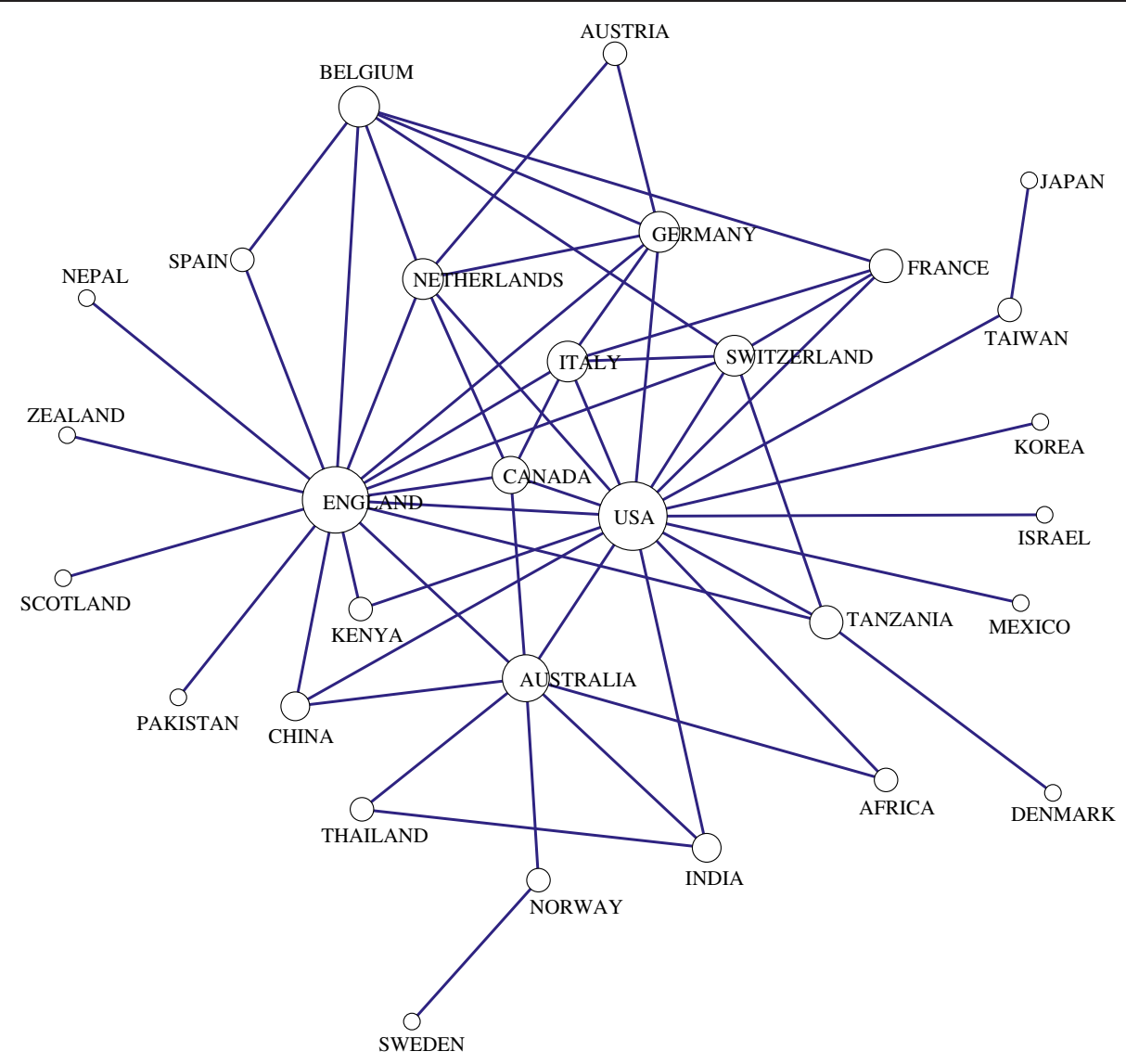

Figure 6 Collaboration among Countries/regions (line value $>3$ ).

strengthening of international cooperation in health management research should be encouraged.

\section{The analysis of collaboration researchers}

The maximum frequency of co-authorship is 8 , which indicate that the collaboration in health management field is not tight comparing with other fields, such as oncology or cardiovascular field $[44,45]$. According to the centrality analysis, researchers such as O'Toole T1, Ascher Ms and Tonat $\mathrm{K} 2$ can be seen as the academic leaders in this field. According to the $\mathrm{N}$-clique analysis and $\mathrm{M}$-core analysis, the majority of researchers are in low $\mathrm{N}$-clique and $\mathrm{M}$-core, which once again proved that the research collaboration in health management research is not tight. The component analysis found that 22 research groups can be regarded as the backbone in this field. Therefore, the researchers in health management should strengthen their collaboration to improve the development and academic level of this field.

\section{The analysis of collaboration research institutions}

Judging from the centrality, 37 research institutions such as UNIV MINNESOTA, USAF, UNIV WASHINGTON and UNIV MARYLAND play an important role in the information dissemination and resources control in health management. Similar to previous study in oncology or cardiovascular field [44-46], while in N-clique and M-core analysis, the frequency of 2- or 3-institutional collaboration is higher, which indicates that it is an irresistible trend that the scientific manpower of different institutions should be integrated. The 8 groups in Figure 5, formed by 33 institutions, co-published more than 3 times, could be regarded as the backbone in this field. It suggests that although to some extent there is collaboration among institutions in health management field, the level is not tight and stable. The government should encourage institutional collaboration to make their respective advantages complementary to each other, thereby, to further enhance the scientific research level. As depicted in Figure 5, extensive research collaboration existed in institutions of different types. For example, collaboration between university and hospital (CONCORD HOSP, UNIV WESTERN AUSTRALIA); collaboration between universities (UNIV FED RIO GRANDE DO SUL, UNIV SAO PAULO, UNIV FED SAO PAULO); collaboration among university, organization and government (WHO, CTR DIS CONTROL \& PREVENT, JOHNS HOPKINS UNIV). 
Table 944 keywords with frequency more than 20

\begin{tabular}{|c|c|c|}
\hline Rank & Keyword & Frequency \\
\hline 1 & PUBLIC-HEALTH MANAGEMENT & 171 \\
\hline 2 & CARE & 120 \\
\hline 3 & MANAGEMENT & 85 \\
\hline 4 & DISEASE & 84 \\
\hline 5 & SYSTEM & 79 \\
\hline 6 & UNITED-STATES & 76 \\
\hline 7 & MODEL & 71 \\
\hline 8 & HEALTH & 68 \\
\hline 9 & RISK & 61 \\
\hline 10 & PREVALENCE & 59 \\
\hline 11 & IMPACT & 57 \\
\hline 12 & RANDOMIZED CONTROLLED-TRIAL & 55 \\
\hline 13 & POPULATION & 53 \\
\hline 14 & QUALITY & 48 \\
\hline 15 & INFECTIONS & 46 \\
\hline 16 & CHILDREN & 43 \\
\hline 17 & ANTHRAX & 42 \\
\hline 18 & MORTALITY & 40 \\
\hline 19 & PERFORMANCE & 40 \\
\hline 20 & SERVICES & 38 \\
\hline 21 & DIAGNOSIS & 37 \\
\hline 22 & INTERVENTION & 36 \\
\hline 23 & RISK-FACTORS & 35 \\
\hline 24 & OUTCOMES & 35 \\
\hline 25 & INHALATIONAL ANTHRAX & 34 \\
\hline 26 & COST & 33 \\
\hline 27 & ADULTS & 33 \\
\hline 28 & SMALLPOX & 32 \\
\hline 29 & PROGRAMS & 32 \\
\hline 30 & WOMEN & 30 \\
\hline 31 & PREVENTION & 29 \\
\hline 32 & TRIAL & 27 \\
\hline 33 & BEHAVIOR & 26 \\
\hline 34 & HEALTH MANAGEMENT & 25 \\
\hline 35 & HEALTH-CARE & 25 \\
\hline 36 & QUALITY-OF-LIFE & 24 \\
\hline 37 & TRANSMISSION & 23 \\
\hline 38 & PHYSICIANS & 23 \\
\hline 39 & RELIABILITY & 22 \\
\hline 40 & PRIMARY-CARE & 22 \\
\hline 41 & IDENTIFICATION & 22 \\
\hline 42 & EPIDEMIOLOGY & 21 \\
\hline 43 & DISEASE MANAGEMENT & 20 \\
\hline 44 & COMMUNITY & 20 \\
\hline
\end{tabular}

The analysis of collaboration countries/regions

According to the $\mathrm{N}$-clique and $\mathrm{M}$-core analysis, international collaboration in health management is becoming an irresistible trend. Previous research showed that economic factor will improve the research collaboration $[47,48]$. And as shown in Figure 6, similar to previous study in oncology or cardiovascular field, those economic powers such as USA, UK are in the center of the network, which play an vital role in the information dissemination and resources control in health management. Although in developing countries/regions, such as China, research about health management started late, it has quickly becoming popular, and a broad collaboration network is forming. At the same time, other countries/regions which are less developed than China should also actively learn and cooperate with economic powers to enhance their scientific research level, change their position in information dissemination and control in this field, and to achieve the global balance development of health management.

\section{Analysis of hot research areas}

To some degree, the frequency of keywords could reflect the hot research areas of health management around the world from 1999 to 2011, providing useful experience for researchers and policy makers. Normally, the highest frequency keywords tend to be the basic words of the field which are unable to be the reference of topic analysis. As the frequency of Public-Health Management and Care are far much higher than other keywords, they are basic words in this study. Besides, the keywords Management, Disease and System having higher frequency reflect the status quo of health management research as well. For instance, Disease shows that management of related diseases (especially Chronic diseases) and preventive care of high-risk groups are the key of health management research while system and model show that the constructions of health management system and model is one of the hot research topics. Risk, Prevalence, and Impact also indicates that researchers focus on the fields of health risk assessment and health management effect evaluation. Therefore, research of health management is mainly reflected in clinical medicine and preventive medicine, which refer to the groups of public, women and children. Research methods are concentrated in statistical analysis such as randomized controlled trials, etc. As for these high-frequency keywords involve cutting-edged issues, covering wide range, the higher scientific research productivity or cooperation of several institutes are one of the effective way to solve the problem.

\section{Limitations}

This study using scientometrics methodology focuses mainly on the research collaboration among authors, institutions and countries/regions in Health Management 


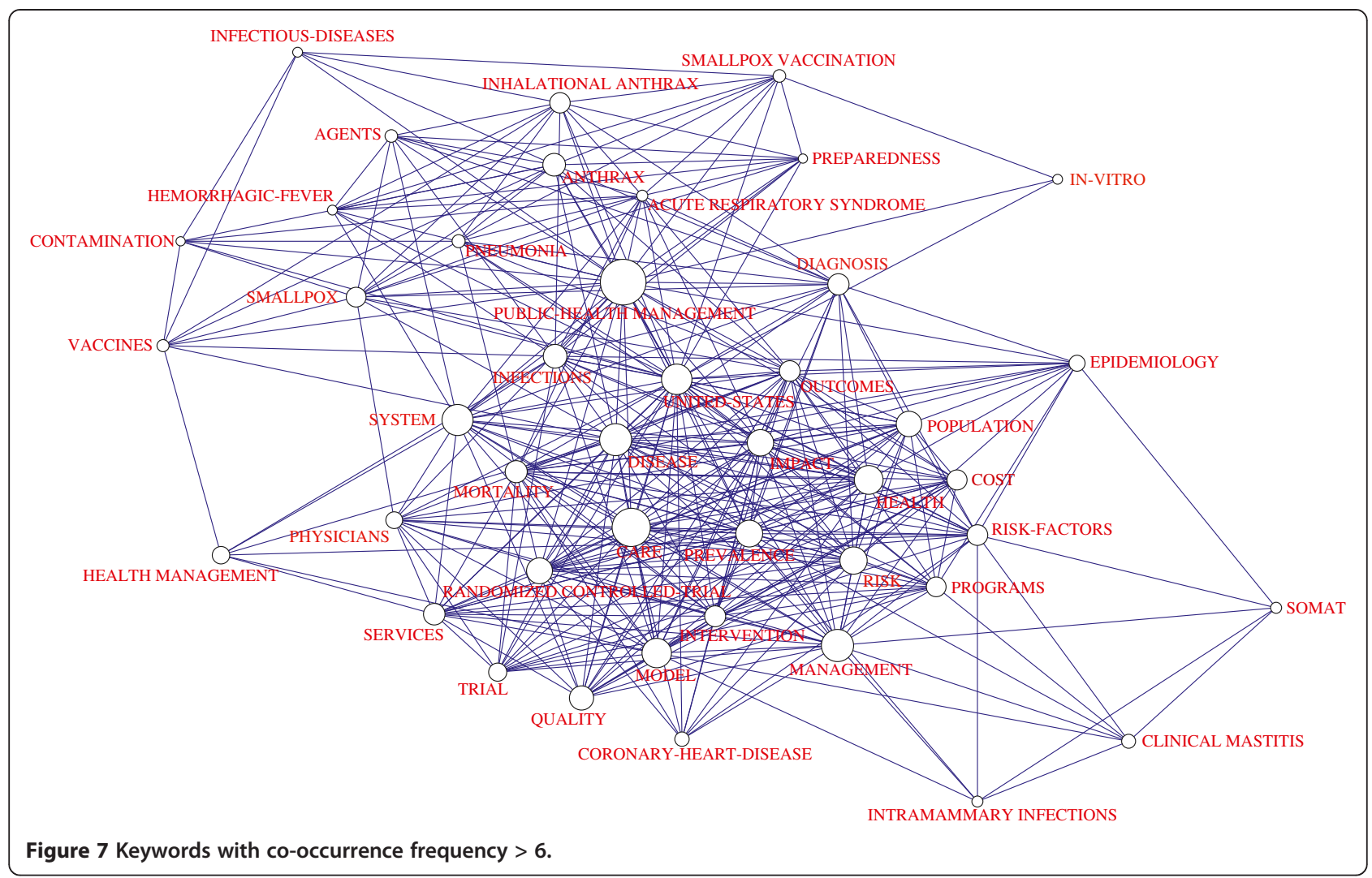

research field with a view to some reference. With limited resources and research levels, this study only searched all the articles in the period 1999-2011 in Web of Knowledge, which content has certain limitations. Methods of SNA, co-authorship etc. are relatively fresh perspective but lacking innovation in this field. And lacking of regularity in the key word selection also impacts the analysis process. Besides, how is the research collaboration related with the research quality of the authors? What factors contribute to research collaboration? All of these need to be further investigated in future study.

\section{Conclusions}

\section{Collaboration in health management field needs to be} enhanced

The number of publications in the health management field is showing a rising trend, especially in recent years. Co-authorship is also keeping growing. And the cooperation of authors is obviously higher than that by institutions and countries. 22 research groups and 37 institutions devoted in this field, among which researchers or research team of USA and UK are in the core position in the collaboration network. Reviewing the related articles in other fields and comparing them with the research results in oncology or cardiovascular field in earlier stage, though $81 \%$ of the articles are produced by scientific cooperation, the Cooperation intensity in the field of health management is still relatively weak, especially between institutions and countries. Therefore, the important way of promoting the progress and internationalization of health management is to strengthen the cooperation between countries and institutions and take full advantage of the core role of dominant groups.

\section{Representative countries and authors are found in the networks}

According to the centrality analysis, researchers such as O'Toole T1, Ascher Ms and Tonat K2 are representative to some extent in health management field. When it comes to institutions, network consisted of UNIV MARYLAND, USAF, CTR DIS CONTROL \& PREVENT, WHO, MINIST HLTH is not only related to different types of institutions, but also shows the complicated relationship among them. Cooperating between countries/regions, USA and UK are in the center of the network which play leading roles in the information dissemination and resources control in health management. In order to provide a basis for the understanding of health management status quo and development trend, researchers should pay attention to the cooperation of representative scholars or institutions. They should also follow the cooperation model to study from the veteran organizations or institutions, take the opportunity of communication and cooperation, so as to promote the further research of 
their country or groups by using experience of countries or regions with developed health management research.

\section{The research topics in health management research}

According to keywords analysis, in spite of its wider range, health management research relatively focuses on the clinical medicine and preventive medicine, which involve the groups of public, women and children. Research methods are also concentrated in statistical analysis such as randomized controlled trials, etc. In health management field of 1999-2011, the hot research topics, helping providing useful experience for researchers and policy makers, included that health risk warning of public, constructions of health management model and system, disease management and effect evaluation of health management, which provide useful basis for research direction.

In conclusion, by scientometrics methodology, this study analysing multiple collaboration types in Health Management research reveals the status quo, points out its defects and then comes up with related suggestions on strengthening cooperation of health management, analyzes the hot research topics as well. These results and proposal would provide an important reference for scholars, policy makers and managers on the aspect of researching and practicing health management deeply.

\section{Competing interests}

The authors declare that they have no competing interests.

\section{Authors' contributions}

The work presented here was carried out in collaboration between all authors. CZ conceived of the study, participated in its design, drafted the manuscript. QY participated in study design, obtained data and contributed to interpretation, and helped draft the manuscript. QF performed the literature search and in the development of the manuscript. ZD provided the theoretical frameworks and performed much of the editing of the manuscript. All authors read and approved the final manuscript.

\section{Acknowledgements}

The research reported in this paper is done as part of the 'Cooperation Analysis of Technology Innovation Team Member Based on Knowledge Network-Empirical Evidence in the Biology and Biomedicine Field' (No. 71103114), which is supported by National Natural Science Foundation of China. And it is also supported by Scientific and Technological Innovation Programs of Higher Education Institutions in Shanxi (No. 20111009).

\section{Author details}

${ }^{1}$ School of Public Health, Shanxi Medical University, South Xinjian Road, Taiyuan, China. ${ }^{2}$ Department of Information Management, Shanxi Medical University, South Xinjian Road, Taiyuan, China. ${ }^{3}$ Division of International Cooperation and Exchange, Shanxi Medical University, South Xinjian Road, Taiyuan, China. ${ }^{4}$ School of Public Health, Shanxi Medical University, South Xinjian Road, Taiyuan, China.

Received: 27 October 2012 Accepted: 19 April 2013

Published: 23 April 2013

\section{References}

1. Melin G, Persson O: Studying research collaboration using co-authorships. Scientometrics 1996, 36:363-77.

2. Vuckovic-Dekic L: Authoship-coauthorship. Arch Oncol 2003, 11:211-2.
3. Subramanyam $\mathrm{K}$ : Bibliometric studies of research collaboration: a review. $J$ Inf Sci 1983, 6:33-8.

4. Katz JS, Martin BR: What is research collaboration? Res Policy 1997, 26:1-18.

5. Chinchilla-Rodríguez Z, Vargas-Quesada B, Hassan-Montero Y, González-Molina A, Moya-Anegóna F: New approach to the visualization of international scientific collaboration. Inf Vis 2010, 9(4):277-287.

6. Moya-Anegón F, Chinchilla-Rodríguez Z, Vargas-Quesada B, CoreraÁlvarez E, González-Molina A, Muñoz-Fernández FJ, Herrero-Solana V: Coverage analysis of Scopus: A journal metric approach. Scientometrics 2007, 73(1):57-58.

7. Chinchilla-Rodríguez Z, Ferligoj A, Miguel S, Kronegger L, Moya-Anegón F: Blockmodeling of co-authorship networks in library and information science in Argentina: a case study. Scientometrics 2012, 93:699-717.

8. Schmoch $U$, Schubert T: Are international co-publications an indicator for quality of scientific research? Scientometrics 2008, 74(3):361-377.

9. Cronin B, Shaw D, La Barre K: A cast of thousands: Coauthorship and subauthorship collaboration in the 20th century as manifested in the scholarly journal literature of psychology and philosophy. J Am Soc Inf SCi Technol 2003, 54(9):855-871.

10. Moody J: The structure of a social science collaboration network: Disciplinary cohesion from 1963 to 1999. Am Sociol Rev 2004, 69(2):213-238

11. Persson O, Glänzel W, Danell R: Inflationary bibliometric values: The role of scientific collaboration and the need for relative indicators in evaluative studies. Scientometrics 2004, 60(3):421-432.

12. Larivière $V$, Gingras $Y$, Archambault $E$ : Canadian collaboration networks: $A$ comparative analysis of the natural sciences, social sciences and the humanities. Scientometrics 2006, 68(3):519-533.

13. Abt HA: The frequencies of multinational papers in various sciences. Scientometrics 2007, 72(1):105-115.

14. Glänzel W, De Lange C: A distributional approach to multinationality measures of international scientific collaboration. Scientometrics 2002, $54: 75-89$.

15. Melin G: Pragmatism and self-organization: Research collaboration on the individual level. Res Policy 2000, 29:31-40.

16. Egghe $L:$ An explanation of the relation between the fraction of multinational publications and the fractional score of a country. Scientometrics 1999, 45:291-310.

17. Kliegl R, Bates D: International collaboration in psychology is on the rise. Scientometrics 2011, 87:149-58.

18. Qin J: An investigation of research collaboration in the sciences through the Philosophical Transactions 1901-1991. Scientometrics 1994, 29(2):219-238.

19. Lundberg J, Tomson G, Lundkvist I, Skar J, Brommels M: Collaboration uncovered: Exploring the adequacy of measuring university-industry collaboration through co-authorship and funding. Scientometrics 2006, 69(3):575-589.

20. Thijs B, Glänzel W: A structural analysis of collaboration between European research institutes. Research Evaluation 2010, 19(1):55-65.

21. Zitt M, Bassecoulard E, Okubo Y: Shadows of the past in international cooperation: Collaboration profiles of the top five producers of science. Scientometrics 2000, 47(3):627-657.

22. Schubert A, Braun T: International collaboration in the sciences, 1981-1985. Scientometrics 1990, 19:3-10.

23. Schubert A, Braun T: International collaboration in the sciences, 1981-1985. Scientometrics 1990, 19:3-10.

24. Hayati Z, Didegah F: International scientific collaboration among Iranian researchers during 1998-2007. Library Hi Tech 2010, 28(3):433-466.

25. Wagner CS, Leydesdorff L: Mapping the network of global science: comparing international co-authorships from 1990 to 2000. Int J Technol Glob 2005, 1(2):185-208.

26. Dore JC, Ojasoo T, Okubo Y, Durand T, Dudognon G, Miquel JF: Correspondence factor analysis of the publication patterns of 48 countries over the period 1981-1992. J Am Soc Inf Sci 1996, 47(8):588-602.

27. Georghiou L: Global cooperation in research. Res Policy 1998, 27(6):611-626.

28. Glänzel W: National characteristics in international scientific coauthorship relations. Scientometrics 2001, 51(1):69-115.

29. Chinchilla-Rodríguez Z, Benavent-Pérez M, de Moya-Anegón F: International collaboration in medical research in Latin America and the Caribbean (2003-2007). J Am Soc Inf Sci Technol 2012, 63(11):2223-2238. 
30. Zheng J, Zhao Z-Y, Zhang $X$, Chen D-Z, Huang M-H, Lei X-P: International scientific and technological collaboration of China from 2004 to 2008: a perspective from paper and patent analysis. Scientometrics 2012, 91:65-80.

31. Toivanen H: Ponomariov B:African regional innovation systems: bibliometric analysis of research collaboration patterns 2005-2009. Scientometrics 2011, 88:471-93.

32. He B, Ding $Y, N i C$ : Mining enriched contextual information of scientific collaboration: A meso perspective. J Am Soc Inf Sci Technol 2011, 62:831-45.

33. Oliveira M, Gama J: An overview of social network analysis. Wiley Interdiscip Rev-Data Mining Knowl Discov 2012, 2:99-115.

34. Uddin S, Hossain L, Abbasi A, Rasmussen K: Trend and efficiency analysis of co-authorship network. Scientometrics 2012, 90:687-99.

35. Kronegger L, Mali F, Ferligoj A, Doreian P: Collaboration structures in Slovenian scientific communities. Scientometrics 2012, 90:631-47.

36. Lee B, Kwon O, Kim HJ: Identification of dependency patterns in research collaboration environments through cluster analysis. J Inf Sci 2011, 37:67-85.

37. Chinchilla-Rodrígueza Z, Vargas-Quesadab B, Hassan-Monterob Y: Antonio, González-Molinab, Félix Moya-Anegóna: New approach to the visualization of international scientific collaboration. Inf Vis 2010, 9(4):277-287.

38. Zhang J, Wolfram D, Wang P, Hong Y, Gillis R: Visualization of healthsubject analysis based on query term co-occurrences. J Am Soc Inf Sci Technol 2008, 59:1933-47.

39. Liu GY, Hu JM, Wang HL: A co-word analysis of digital library field in China. Scientometrics 2012, 91:203-217.

40. Zhao L, Zhang Q: Mapping knowledge domains of Chinese digital library research output, 1994-2010. Scientometrics 2011, 89:51-87.

41. Ding Y, Chowdhury GG, Foo S: Bibliometric cartography of information retrieval research by using co-word analysis. Information Processing \& Management 2001, 37:817-42.

42. Sternitzke C, Bergmann I: Similarity measures for document mapping: A comparative study on the level of an individual scientist. Scientometrics 2009, 78:113-30

43. Qi Y, Hongfang S, Zhiguang D: The research collaboration in Chinese cardiology and cardiovasology field. Int I Cardiol. doi:10.1016/ j.ijcard.2012.03.019.

44. Qi Y: Hongfang Shao, Zhiguang Duan: Research groups of oncology coauthorship network in China. Scientometrics 2011, 89:553-67.

45. Qi Y, Hongfang S, Zhiguang D: The research collaboration in Chinese cardiology and cardiovasology field. Int I Cardiol. In Press.

46. Wang Y, Wu Y, Pan Y, Ma Z, Rousseau R: Scientific collaboration in China as refected in co-authorship. Scientometrics 2005, 62(2):183-198.

47. Stokes TD, Hareley JA: Co-authorship, social structure and influence within Specialities. Soc Stud Sci 1989, 19:101-125.

48. Michael EB, Stephen BJ, Jonathan WK, Kathleen MC, Frank K, Jacqueline AM: Evolution of Coauthorship in Public Health Services and Systems Research. American Journal of Preventive Medicine 2011, 41(1):112-117.

doi:10.1186/1472-6947-13-52

Cite this article as: Zhang et al:: Research collaboration in health management research communities. BMC Medical Informatics and Decision Making 2013 13:52.

\section{Submit your next manuscript to BioMed Central and take full advantage of:}

- Convenient online submission

- Thorough peer review

- No space constraints or color figure charges

- Immediate publication on acceptance

- Inclusion in PubMed, CAS, Scopus and Google Scholar

- Research which is freely available for redistribution 